\title{
Acoustical analysis of vowel duration in Palestinian Arabic speaking aphasics
}

\author{
Hisham Adam \\ Liberal Arts Department, American University of the Middle East, Kuwait City, Kuwait
}

\section{Email address:}

Hisham.al-adam@aum.edu.kw

\section{To site this article:}

Hisham Adam. Acoustical Analysis of Vowel Duration in Palestinian Arabic Speaking Aphasics. American Journal of Psychiatry and Neuroscience. Vol. 2, No. 1, 2014, pp. 13-17. doi: 10.11648/j.ajpn.20140201.13

\begin{abstract}
The current study investigates vowel durations of Arabic- speaking Broca's aphasics. Three subjects diagnosed with Broca's aphasia and three normal speakers participated in this study. Vowel durations of the short Arabic vowels (/i/, $/ \mathrm{a} /, / \mathrm{u} /$ ) preceding voiced and voiceless fricatives were measured and analyzed. The effects of voicing on vowel duration are also investigated. The results show that the normal speakers as well as Broca's aphasics complied with the phonological rule, vowels being longer preceding voiced fricatives. It is also demonstrated that vowel durations were significantly greater for Broca's aphasics compared to normal speakers. Finally, this study is brought to bear on several aspects concerning timing and prosodic impairments of Broca's aphasic speech. The finding may also have clinical applications concerning speech and language therapy in Palestine.
\end{abstract}

Keyword: Vowel Production, Aphasia, Vowel duration, Neuroscience, Cognition

\section{Introduction}

Much research has been devoted to investigate the durational and articulatory parameters of speech segments. It has been found that several aspects of vowel temporal parameters, including vowel duration, fundamental frequency, and formant frequency, are highly affected by speech intelligibility in both normal and disordered speech $[12,36,24]$. Vowel duration contributes to the listener's ability to perceive vowels, in addition to providing information about vowel production mechanisms [15]. For example, it has been found that reduction of vowel duration accompanied by lax vowels compared to tense vowels is a result of decreased articulatory configurations required for the producing lax vowels [15].Accordingly, the measurements of vowel duration may demonstrate the degree of articulatory movements required to produce a particular vowel.

Acoustic investigations also indicate that vowel duration is a perceptual cue for vowel identification and speech intelligibility [8,27]. Ferguson and Kewley-Port [8]reported from a significant impact of speech intelligibility on vowel duration, where vowels were perceived to be longer in sentences and phrases produced in a conversational style compared to those were addressed to individuals with hearing loss [9]. The acoustic literature reported from various temporal patterns concerning vowel duration. For example, it has been found that high vowels are shorter than low vowels, while vowels occur in open syllables are longer than vowels accruing in closed syllables [19]. Furthermore, vowels preceding voiced consonants were found to be longer compared to those preceding voiceless sounds, while vowels before fricatives are longer than vowels preceding stop consonants [19]. Vowel duration also was found to be affected by pitch and rate of speech. It has also been found that vowels spoken at slower rate were significantly longer compared to those spoken at faster rate[23].

Several studies have been carried out on the temporal and articulatory disturbances characterizing speakers with Broca's aphasia and apraxia of speech [17, 5, 3]. In general, these investigations have raveled that Broca's aphasic speech is agrammatic, nonfluent and dysprosodic. Broca's aphasic speech is also characterized by a slow speaking rate with segment and syllable durations all being longer than those for healthy speakers $[6,3]$.

Vowel durations were found to be significantly longer among Broca's aphasics compared to normal speakers. It has been proposed that Broca's aphasics revealed temporal impairments, particularly abnormal lengthening of all speech segments [33]. In contrast, other studies found that Broca's aphasics and speakers with apraxia of speech were able to maintain the intrinsic duration differences between tense and lax vowels and the durational patterns are 
comparable to those from the normal speaker [10]. Vowel duration in multisyllabic words and phrases were significantly longer for the aphasic speakers compared to the non-brain-damaged control group [30]. In contrast, in a study on vowel duration for monosyllabic words as produced by Broca's aphasics, it has been found that vowel durations were comparable to the control group [31]. This inconsistency of the results concerning the durational patters of vowels can be interpreted in terms of the differences in the methodological research approaches of these studies. As it can be seen, temporal parameters, including vowel durations are important to understand the underlying mechanisms of Broca's aphasics timing deficits.

Vowel length in Arabic is phonologically significant. That is, Arabic contrast between short and long vowels, resulting in meaning differences. For example, the words [Qa:1] said and [qal] 'decreased' have different meanings, emphasizing that vowel length in Arabic is phonologically distinctive [13]. Accordingly, characterizations of Broca's aphasic speech, particularly the prosodic and temporal parameters are language specific [10]

\section{Methods}

\subsection{The Aims of the Study}

The current study aims to (a) investigate vowel durations as produced by Palestinian Broca's aphasics compared to normal speakers; (b) to examine whether or not there are differences between average duration of vowels produced by Broca's aphasics compared to the normal speakers; and (c) to examine the extent to which the duration patterns in Palestinian Broca's aphasics are consistent with results reported from other languages.

It was hypothesized that:

1-. Broca'saphasics would produce longer vowel durations compared to normal speakers

2-. Voicing would affect vowel quality, by having longer vowel durations prior voiced fricatives compared to voiceless ones.

\subsection{Subjects}

Three male agrammatic Palestinians residing in the West Bank participated in the study. The participants were diagnosed as Broca's aphasics using the Jordanian Arabic version of the Bilingual Aphasia Test [29]. Three native speakers with no language or speech deficits served as the control group. All participants were right-handed and presented with left hemisphere lesion at least six months prior to testing. They revealed typical symptoms of Broca's aphasia, including non-fluent, effortful and telegraphic speech. As shown in Table 1, the ages of the participants ranged from 49 to 58 years. The time post-onset ranged from one to eight years, and their number of educational years ranged from 10 to 15 . Visual and auditory systems functioned to a sufficient degree to complete the experimental tasks of the study.
Table 1. Persons with aphasia.

\begin{tabular}{ccccc}
\hline Subject & Age & Etiology & MPO & Gender \\
\hline A.B & 49 & CVA-L & 13 & M \\
D.S & 55 & CVA-L & 22 & M \\
W.D & 58 & CVA-L & 70 & M \\
\hline
\end{tabular}

Details of the participants. Participant data: (A: person with aphasia; CVA: Cerebro-vascular accident; L: left hemisphere; MPO: months post-onset; M: male).

\subsection{Stimuli}

The short vowels [a] [u], and [i] were examined and investigated. Target vowels were embedded in a (CVC) syllable structure, in which vowels are preceded by initial voiced and voiceless fricatives [z] and [s]. The list of words is given in Table 2. Monosyllabic words in a CVC structure were chosen to avoid duration increase as the number of syllables increased. The target vowels were embedded in the carrier sentence "Piћki" ("Say") since vowels are found to be longer when produced in isolation [1]. Participants were instructed to speak at normal pitch and loudness as they were able. Vowel duration was measured milliseconds (ms) and selected from the steady sate of the vowel to the offset of the vowel. Each vowel was produced 6 times, yielding a total of 216 (6 words $\times 6$ repetitions $\times 6$ subjects) productions. The utterances were recorded in a quiet place at a sampling rate $44 \mathrm{~Hz}$, using PRAAT [4] and Phono-Lab [25]. Tokens were phonetically transcribed by the researcher and an experienced speech and langue pathologist.

Table 2. Stimuli.

\begin{tabular}{|c|c|}
\hline \multicolumn{2}{|c|}{ Target vowels and consonants } \\
\hline Vowel & Consonants \\
\hline $\mathrm{i}$ & $\underline{\operatorname{sid}} / \underline{\text { zid }}$ \\
\hline $\mathrm{u}$ & $\underline{\text { sud}} / \underline{\text { zud }}$ \\
\hline $\mathrm{a}$ & $\underline{\mathrm{sad}} / \underline{\mathrm{zad}}$ \\
\hline
\end{tabular}

\section{Results and Discussion}

Table 3 demonstrates the mean vowel duration and standard deviation for monosyllabic words (CVC). The statistical analysis demonstrated that there was a significant effect of Voicing on Vowel Duration $[F(1,19)=12.06$, $p$ $=.004]$ for both the normal speakers and the Broca's aphasics. Vowels preceding voiced fricatives were significantly longer than those preceding voiceless fricatives for both the normal speakers and Broca's aphasics(88 $\mathrm{ms}$ and 159$)$ respectively. 
Table 3. Mean vowel durations ( $m s$ ) and Standard deviations preceding voiced and voiceless fricatives for the control group $(C)$ and the aphasic subjects $(A B, D C, W D)$.

\begin{tabular}{ccc}
\hline \multirow{2}{*}{ Subject } & \multicolumn{2}{c}{ Place of Articulation } \\
\cline { 2 - 3 } & \multicolumn{2}{c}{ Alveolar } \\
& SD \\
\hline Voiced & 134 & 12 \\
C & 194 & 33 \\
AB & 222 & 40 \\
DC & 234 & 34 \\
WD & $/ S /$ & \\
Voiceless & 88 & 9 \\
C & 133 & 55 \\
AB & 166 & 44 \\
DC & 180 & 55 \\
WD & &
\end{tabular}

In fact, controversial results were found concerning the effect of voicing on vowel duration in Arabic. For example, in a study on Gulf Arabic vowels preceding voiced consonants were not significantly longer than those preceding voiceless consonants [16]. This finding is also consistent with results reported from Jordanian Arabic and Saudi dialect $[26,9]$. In contrast, in a study examined the effect of voicing on vowel duration on Ghamid Saudi dialect it has been found that vowels preceding voiced consonants were significantly longer than those before voiceless ones[1]. It is worth noting here that the effect of voicing on vowel duration in Arabic is still a controversial issue, which might be due to research methodological approaches, concerning data collection and analysis in addition to dialect-specific aspects of Arabic varieties.

As noted by normal speakers, shorter vowel durations were found for the short vowel $[\mathrm{u}]$ compared to the high front vowel [i], while Broca's aphasics produce the vowel [i] with shorter duration compared to the vowel $[\mathrm{u}]$. The control group and Broca's aphasics have produced the low vowel [a] with the longest duration compared to the vowels understudy. However, it is must be mentioned that Broca's aphasics have produced the vowel [a] with shorter duration compared to the normal speakers, indicating that the degree of jaw lowering has a positive impact on vowel duration[20]. That is, low vowels are produced with a high degree of law lowering, making them longer compared to other vowels. The fact that Broca's aphasics have produced low vowels with shorter durations may suggest poor vowel targeting due to insufficient jaw excursion to produce low vowels precisely [14]. It is clear that vowel duration considered an important variable in speech perception and the findings of the current study that vowels are longer before voiced fricatives are in accordance with results reported from other languages [15]. Broca's aphasic speech is characterized by slow and effortful speech, resulting in increased vowel durations which suggest motor planning and temporal control deficits [2].

Findings of the current study indicate that long vowel duration may be also attributed to slow speech style exhibited by Broca's aphasics and their self-monitoring strategy [32]. Investigations and analysis of literature data proposed that slowing of rate indicates auditory processing impairments and motor timing impairments, including abnormally long vowel durations [28].

The results of vowel durations also show a wide variability among the aphasic subjects and greater vowel durations compared to the normal speakers, suggesting that mechanisms of temporal abnormalities among Broca's aphasics are primarily phonetic rather than phonological planning impairments $[22,35]$. In fact, a number of studies have suggested that Broca's aphasic's impairments are due to temporal coordination and timing deficits of articulatory movements [21, 34]. Results of these studies have indicated that these deficits affect speech production mechanisms, characterized by slow rate of speak, and excessive segments duration. This suggests that insufficient tactile feedback during the production of vowels may contribute to long vowel durations, indicating that Broca's aphasics are uncertain about the required articulatory movements for vowel production [37]. Kent and Rosenbek[17] suggested that the greater vowel durations and prolongation of articulatory segments can be partially contributed to impairments in accessing and retrieving information concerning the articulatory target.

Nevertheless, other timing and prosodic parameters including voice onset time, rhythm, stress and fundamental frequency should be examined to determine whether Broca's aphasics' deficits are arising at the segmental or suprasegmental level and whether their prosodic deficits are associated with speech perception abilities. It must be noted, however, that the current study has investigated only vowels embedded in monosyllabic words, thus precluding investigation for the impact of word length on vowel duration.

\section{Conclusion}

The overall objective of the current study was to examine vowel durations for Broca's aphasics compared to normal speakers. The means of the duration of vowels produced by Broca's aphasics were significantly longer than those produced by normal speakers. The acoustic analysis showed a significant impact of voicing on vowel duration as shown by normal speakers and Broca's aphasics as well as, whereby vowels preceded by voiced consonants were longer than those preceded by voiceless ones. This finding is inconsistent with results reported from studies on other Arabic varieties. The excessive vowel durations may suggest that mechanisms of temporal abnormalities among Broca's aphasics are primarily phonetic rather than phonological planning impairments.

However, the current study was limited to three male aphasics and therefore it can be considered only as a preliminary look at the production of vowels by Palestinian aphasics. Further research should include more subjects and investigate other linguistic factors, including syllable structure, vowel length contrast, formants frequencies, 
stress, and coarticulation. Nevertheless, this study was an attempt to provide new insights on vowel production in cross neurolinguistic research in various languages, given the fact that Palestinian Arabic is less investigated compared to other Arabic varieties.

\section{References}

[1] Alghamdi M: A spectrographic analysis of Arabic vowels: A cross-dialect study. Journal of King Saud University: Arts 1998, 10: 3-24.

[2] Baum: Consonant and vowel discrimination by braindamaged individuals: Effects of phonological segmentation. Journal of Neurolinguistics2002, 15: 447-461.

[3] Baum, S., \& Boyczuk, J: Speech timing subsequent to brain damage: Effects of utterance length and complexity. Brain and Language 1999, 67: 30-45.

[4] Boersma, P. \&Weenink, D: Praat: Doing phonetics by computer (version5.1.43) [computer program]. Retrieved from /http://www.praat.org, 2010.

[5] Collins, M., Rosenbek, J., \& Wertz, R: Spectrographic analysis of vowel and word duration in apraxiaof speech. Journal of Speech and Hearing Research, 1983, 26: 217-224.

[6] Danly, M., \& Shapiro, B: Speech prosody in Broca's aphasia. Brain and Language 1982, 16: 171-190.

[7] Dressler, R., Buder, E., Cannito, M., Marquardt, T., \& Strauss, M: Variability inrepeated word productions: Comparing speakers with fluent and nonfluent aphasia. Poster presented at the 10th Biennial Conference on Motor Speech, SanAntonio, TX, 2000.

[8] Ferguson, S., \&Kewley-Port, D: Talker differences in clear and conversational speech: Acoustic characteristics of vowels. Journal of Speech, Language, and Hearing Research2007, 50: 1241-1255.

[9] Flege, J. \& Port, R: Cross-language phonetic interference: Arabic toEnglish. Language and Speech1981, 24:125-146.

[10] Gandour J., \& Dardarananda, R: Prosodic Disturbance in Aphasia: Vowel Length in Thai. Brain and Language1984b,23: 206-224.

[11] Goodglass, H., \& Kaplan, E: The assessment of aphasia and related disorders. Philadelphia: Lea and Febiger, 1972.

[12] HazanV.,\& Markham, D: Acoustic-phonetic correlates of talker intelligibility for adults and children. Journal of the Acoustical Society of America2004, 102:3108-3118.

[13] Hetzron: The Semitic Languages. New York: Routledge, 1983.

[14] Hixon, T., Weismer, G., \&Hoit, J: Preclinical speech science: Anatomy, physiology, acoustics, perception. San Diego, CA: Plural Publishing Inc, 2008.

[15] House, A: On vowel duration in English. Journal of the Acoustical Society of America, 1961, 33: 1174-1178.

[16] Hussain, A: An experimental investigation of some aspects of the sound systemof the Gulf Arabic dialect with special reference to duration. Thesis (PhD) University of Essex1985.
[17] Kent, R., \& Rosenbek, J: Prosodic disturbance and neurologic lesion. Brain and Language 1982, 15: 259- 291.

[18] Ladefoged ,P: Preliminaries to Linguistic Phonetics. Chicago: University of Chicago Press, 1971.

[19] Ladefoged, P: A course in phonetics. 5th ed. Boston: Wadsworth, 2006.

[20] LindblomB: Vowel duration and a model of lip mandible coordination. Quaterly Progress \& Staus Report Speech Transmission Laboratory 1967, 4: 1-29.

[21] Lehisie, I: Suprasegmentals. M.I.T. press, 1970.

[22] Luria, A: Higher Cortical Functions in Man. New York: Basic Books, 1966.

[23] Magen, H. \& Blumstein, S: Effects of speaking rate on the vowel length distinction in Korean. Journal of Phonetics 1983, 21: 387-409.

[24] Maxwell, O., \& Fletcher, J:Acoustic and durational properties of Indian English vowels. World English 2009, 28: 52-69.

[25] Metoui, M: Phono Lab: Computer program zurArtikulatorisch-Akustischen Date nanalyse. Arbeitsberichte des InstitutsfürAllgemeine und Vergleichende Sprachwissenschaft der Universität Mainz 1995, 1: 1-100.

[26] Mitleb, F: Vowel length contrast in Arabic and English: A spectrographictest. Journal of Phonetics 1984, 12: 229-235.

[27] Mok, P: Effects of vowel duration and vowel quality on vowel-to-vowel coarticulation. Language and Speech 2011, 5: 527-545.

[28] Mysak, E: Pathologies of the speech systems. Baltimore, MD: Williams \& Wilkin, 1976.

[29] Paradis, M: The assessment of bilingual aphasia. Hillsdale, NJ: Lawrence Erlbaum Associates1987.

[30] Ryalls, J: Motor Aphasia: Acoustic Correlates of Phonemic Disintegration in Vowels. Neuropsychologia 1981,19:365-374.

[31] Ryalls, J: An Acoustic Study of Vowel Production in Aphasia. Brain andLanguage 1986, 29: 48-67.

[32] Seddoh, S: Prosodic disturbance in aphasia: speech timing versus intonation production. Clinical Linguistics \& Phonetics2004, 18: 17-38.

[33] Seddoh, S: Conceptualisation of deviations in intonation production in aphasia. Aphasiology 2008, 22:1294-1312.

[34] Shankweiler D., Harris, K., Ni, W, Byrd, D., \&Avrutin, S: Production inBroca's aphasia: A case study of syntactic and phonetic aspects. Brain and Language 1996, 55: 14-16.

[35] Shinn, P., \& Blumstein, S: Phonetic disintegration in aphasia: Acoustic analysis of spectralcharacteristics for place of articulation. Brain and Language 1983, 20: 90-114.

[36] TsaoY.,Weismer, G., \&Iqubal, K: The effect of intertalker speech rate on acoustic vowel space. Journal of the Acoustical Society of America 2006, 119:1074-1082.

[37] Williams S., \& Seaver, J: A comparison of speech sound durations in three syndromes of aphasia. Brain and 
Language1986, 29: 171-182. 